\title{
Influence of probable precipitation futures on strawberries (Fragaria $x$ ananassa): Results from a simulated rainfall experi- ment
}

\author{
Rachel E. Schattman ${ }^{1 *}$, Alicyn Smart ${ }^{2}$, Sean Birkel ${ }^{3}$, Haley Jean ${ }^{4}$, Kallol Barai ${ }^{5}$ and Yong-Jiang Zhang ${ }^{2, *}$ \\ 1 University of Maine School of Food and Agriculture Agroecology Lab, University of Maine George J. Mitch- \\ ell Center for Sustainability Solutions; rachel.schattman@maine.edu \\ 2 University of Maine Extension; alicyn.smart@maine.edu \\ 2 University of Maine Climate Change Institute, University of Maine Extension; birkel@maine.edu \\ 2 University of Maine School of Food and Agriculture Agroecology Lab; haley.jean@maine.edu \\ 2 University of Maine School of Biology and Ecology; kallol.barai@maine.edu \\ 2 University of Maine School of Biology and Ecology; yongjiang.zhang@maine.edu \\ * Correspondence: rachel.schattman@maine.edu
}

\begin{abstract}
It is well established that the interacting effects of temperature and precipitation will alter agroecological systems on a global scale. These shifts will influence the fitness of specialty crops, specifically strawberries (Fragaria $x$ ananassa), an important crop in the Northeastern United States. In this study, four precipitation scenarios were developed that are representative of current and probable-future growing season precipitation patterns. Using a precipitation simulator, we tested these scenarios on potted day neutral strawberries. This study generated four primary results: (1) though treatments received different amounts of precipitation, little difference was observed in soil volumetric water content or temperature. However, treatments designed to simulate future conditions were more likely those designed to simulate current conditions to have higher nitrate-in-leachate (N-leachate) concentrations; (2) neither total precipitation nor seasonable distribution were associated with foliar or root disease pressure; (3) while there was a slightly higher chance that photosynthetic potential and capacity would be higher in drier conditions, little difference was observed in the effects on chlorophyll concentration, and no water stress was detected in any treatment; and (4) leaf biomass was likely more affected by total rather than seasonal distribution of precipitation, but interaction between changing rainfall distribution and seasonal totals is likely to be an important driver of root biomass development in the future.
\end{abstract}

Keywords: Climate change, agroecology, Fragaria $x$ ananassa, precipitation, rainfall simulation

\section{Introduction}

Internationally, the United States is ranked second in strawberry (Fragaria $\mathrm{x}$ ananassa) production, producing $20 \%$ of the global market and generating $\sim 2.3 \mathrm{~B}$ USD gross sales annually. In the Northeast, strawberries are produced on $\sim 1,538$ hectares $(3,800$ acres) for wholesale and direct markets. In this region, strawberry production in this region is most commonly integrated with diversified farming operations, with the average production area per farm at 0.61 hectares ( 1.5 acres). Production areas are commonly located around high-population centers, suggesting the important role that strawberries play in meeting a fresh and regional market demand. While nearly all of the strawberries produced in the Northeast are consumed within the region, only $95 \%$ of strawberries purchased in Northeast states are grown there [1]. This means there are significant opportunities for growers and the agricultural advisors who support them to address current production challenges and increase production to better meet local consumer demand. 
Temperature and solar radiation have been shown to be important limiting factors in strawberry yield efficiency [2], however, crop-water use is also important [3]. It is estimated that strawberries require $2.54 \mathrm{~cm}$ (1 inch) of water every 12-14-days during the growing season (April - October in the Northeastern United States), increasing to $3.81 \mathrm{~cm}$ (1.5 inches) of water every 7-days during the fruiting period [4]. Increasingly, growers in the Northeast are using protected cultivation to produce strawberries (i.e. low-tunnels, high tunnels, and greenhouses) in order to protect and enhance fruit marketability, reduce disease pressure, increase both total yield and the size of individual fruits, extend fruit production, and control phenological development [5]. However, it is still common for strawberry growers to produce their crops in unprotected environments, in which case strawberries remain vulnerable to precipitation and temperature extremes and the associated challenges these extremes present.

Shifting precipitation patterns is widely accepted as one of the most consequential effects of anthropogenic climate change [6]. Globally, it is expected that these shifting precipitation patterns will influence both ground and surface water resources, and by extension agroecological systems. Surface water reliability in particular is expected to change due to increased variability in precipitation patterns [7]. Groundwater sources are less prone to changing and variable precipitation than surface waters, however they are still vulnerable. Groundwater reservoirs are often more spatially dispersed, and serve as important reserves during periods when surface water bodies are unavailable or unreliable. They are also difficult to monitor, and can be expensive to access through drilling and pumping [8]. Groundwater use is considered sustainable when the rate of withdrawal does not exceed the rate of recharge. However, climate change is anticipated to affect recharge mechanisms (i.e. precipitation, temperature, and sea level) thereby drawing into question the reliability of some regionally-important groundwater reservoirs [9]. This is of considerable concern in regions where there is a high reliance on groundwater for municipal, industrial, and agricultural purposes.

The Northeast region of the United States is one such region. The Northeast comprises 12-states (Connecticut, Delaware, Maine, Maryland, Massachusetts, New Hampshire, New Jersey, New York, Pennsylvania, Rhode Island, and Vermont) as well as the District of Columbia (figure 1). Since 2001, this region has experienced a notable increase in both total annual precipitation and extreme precipitation $[10,11]$, outpacing changes observed in other parts of the United States [12]. Extreme precipitation has been increasing, both in terms of the number of extreme events and the intensity of these events [13]. Along with an increase in seasonal extreme rainfall events, it is anticipated that increasingly common dry periods and drought will affect water resources across the region [14], and that water use efficiency and access will become an increasingly important consideration for agricultural sectors [15], including in small fruit production systems. 


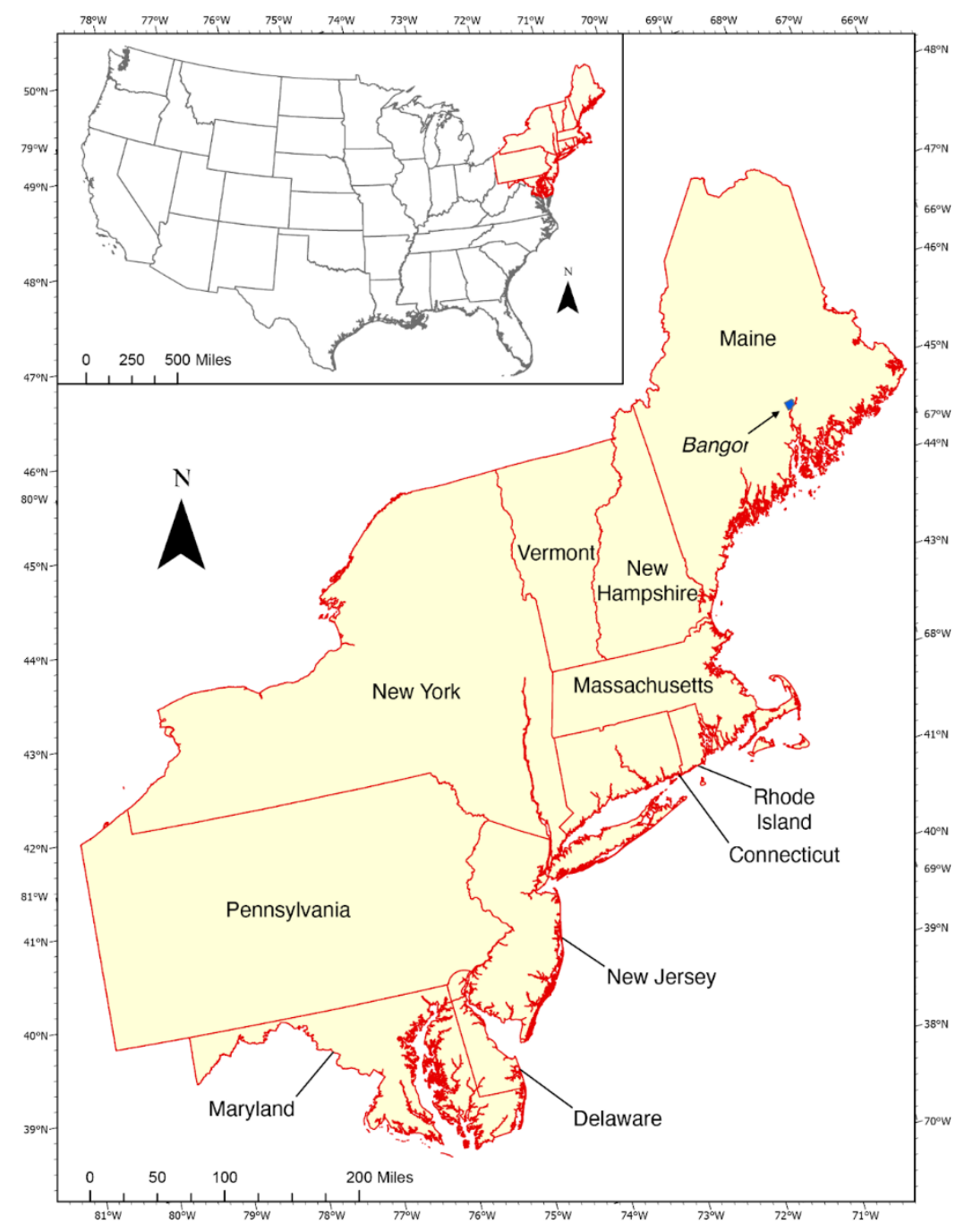

Figure 1. This study focuses on agricultural production and precipitation scenarios relevant to the Northeast region of the United States. Bangor, Maine (site of GHCN station USW00014606) is indicated with the blue box.

It is well established that both water availability (i.e. soil-water potential) and the relationship between water absorption and transpiration rates have direct effects on crop physiological performance [16]. Precipitation is an important driver of soil-water potential that influences water availability for agriculture, and provides necessary moisture for primary crop physiological development. In addition, precipitation during the non-cropping season in the form of rain or snowfall contributes to ground- and surface-water reservoirs, which can later be utilized for irrigation, fertigation, or frost protection. Small fruit specialty crops are particularly vulnerable to changes in precipitation (frequency and intensity) during critical growth periods. For example, strawberries are sensitive to yield loss and quality degradation as a result of disease (related to excess water) and poor fruit development (related to both limited and excess water) [17]. Even for crops with high resilience to drought such as wild blueberries in Northeast USA, water deficits will greatly impact the crop vigor and yield [18].

To meaningfully assess the effects of changing precipitation patterns on specialty crops in general, and strawberries in particular, we must look at both crop yield and a broader range of plant quality and agroecological outcomes [19]. Assessing environmental conditions (e.g. soil water potential) and plant physiological functions (e.g. photosynthesis indicated by chlorophyll fluorescence, chlorophyll concentration) generates important insights into crops' resistance to a changing climate. For example, high strawberry 
root mass density has been shown to increase nutrient uptake, with root mass density being associated with soil water potential [20]. Sub-seasonal root biomass shrinkage in this crop is associated with fruiting periods, a time when nutrient needs are also likely at their highest [21]. It is likely that changes in biomass are influenced by soil water potential, and have subsequent effects on strawberries' ability to metabolize nutrients and perform core physiological functions. In another example, chlorophyll concentration of leaves is considered to be a reliable indicator of photosynthetic capacity, and has been found to be positively correlated with photosynthetic $\mathrm{CO} 2$ fixation [22], as well as yield [23]. Estimation of leaf chlorophyll concentration allows researchers to estimate not only plants' photosynthetic capacity, but also the effects of disease, nutritional, or environmental stress $[24,25]$. Though chlorophyll content has been positively associated with yield in some crops [26], it is estimated that, under periods of water stress, photosynthetic activity decreases [27], likely leading to decreased yield and crop quality.

Considering the complexity of these dynamics, and the likely sensitivity of strawberries to changes in precipitation and water applications, the objectives of this research were to determine the influence of four precipitation scenarios on the production of strawberries. Specifically, we aimed to understand how strawberries perform under different precipitation scenarios in terms of (a) total leachate amounts and loss of nitrate through leaching, (b) incidents of disease and insect damage, and (c) plant physiological performances including chlorophyll concentration and photosynthesis in strawberries.

\section{Methods}

\subsection{Experimental design}

A small-scale, portable rainfall simulator was constructed, using a design adapted from Humphry et al. [28]. A single, stationary nozzle was mounted on the steel frame at a height of $3.048 \mathrm{~m}\left(10^{\prime \prime}\right)$. The base area of the simulator was $1.5 \times 2 \mathrm{~m}\left(4.9^{\prime} \times 6.7^{\prime}\right)$. Simulated precipitation was calibrated by assessing the length of time the simulator needed to run to fill empty pots to $4,921 \mathrm{ml}\left(1^{\prime \prime}\right)$ at a PSI between $5-8$. The selected setting precipitated a rate of $289 \mathrm{ml} / \mathrm{minute}$ (17 minutes to fill to $\left.1^{\prime \prime}\right)$. Deionized water was used for the experiment, pumped through the simulator using a small Shurflo pump at 3.5 gallons per miniature and a maximum of $310.26 \mathrm{kPa}$ (45 PSI).

The treatment schedules in this study follow four plausible future rainfall scenarios (table 1) derived from daily precipitation during the warm season (1 April 1st - 30 September) for the years 2001 and 2019 observed at the Bangor International Airport $\left(44.8^{\circ} \mathrm{N}\right.$, $-68.82^{\circ} \mathrm{W}$; elevation 58 meters $\left(190^{\prime}\right)$, Maine (figure 1), a site located within the southern interior climate division. Precipitation data are from the Global Historical Climatology Network (GHCN) [29], station USW00014606. The first two scenarios represent plausible future precipitation regimes following the historically dry (RECDry) and wet (RECWet) conditions observed in 2001 and 2019, respectively. In 2001, modest intervals of rainfall were interspersed between dry intervals ranging two to four weeks duration. Only a single rainfall event, $4.70 \mathrm{~cm}$ (1.85 inches) on 25-September, exceeded a $2.54 \mathrm{~cm}$ (1 inches) threshold that season. This is in contrast to 2019, which saw frequent rainfall throughout the warm season, and eight instances of daily rainfall $>6.38 \mathrm{~cm}(2.51$ inches $)$. The third and fourth plausible future scenarios are based on the 2001 precipitation, but where daily values are increased by the factors 1.43 (AMPDry1.43) and 1.89 (AMPDry1.89) to align with a season total equivalent to that observed for the historically wet year 2019. Thus, these latter two scenarios represent plausible future climates where most of the season precipitation is accumulated during heavy rainfall events that are separated by extended intervals of dryness. In AMPDry1.89, the 25-September rainfall event noted above is removed such that all other daily rainfall values must be increased in order for the season total to reach that observed in 2019. AMPDry1.43 and AMPDry1.89 are taken to represent plausible conditions in 2050 and 2100, respectively. 
Table 1. Precipitation scenarios used as independent variables

\begin{tabular}{|c|c|}
\hline Treatment & Description of treatment development \\
\hline RECDry & $\begin{array}{l}\text { Based on observations } 2001 \text { - infrequent rainfall separated by prolonged periods } \\
\text { ( } 2-5 \text { weeks }) \text { of dryness. Daily rainfall above } 2.54 \mathrm{~cm} \text { ( } 1 \text { inch) occurred only once } \\
\text { in an event of } 4.70 \mathrm{~cm} \text { ( } 1.85 \text { inches }) \text { on } 25-S e p t e m b e r \text {. Total rainfall April-Septem- } \\
\text { ber rainfall }=29.95 \mathrm{~cm} \text { ( } 11.79 \text { inches). }\end{array}$ \\
\hline RECWet & $\begin{array}{l}\text { Based on observations } 2019 \text { - frequent moderate intensity rainfall events distrib- } \\
\text { uted throughout the growing season without any prolonged dryness. Rainfall ex- } \\
\text { ceeding } 2.54 \mathrm{~cm} \text { ( } 1 \text { inch) occurred on eight separate days. Total April-September } \\
\text { rainfall }=72.85 \mathrm{~cm} \text { ( } 28.68 \text { inches). }\end{array}$ \\
\hline AMPDry1.43 & $\begin{array}{l}\text { Modified from observed } 2001 \text { precipitation - daily values multiplied by } 1.43 \text { to } \\
\text { increase total growing season rainfall to match that observed in } 2019 \text { ( } 72.85 \mathrm{~cm} \text {; } \\
28.68 \text { inches), while preserving the seasonal distribution observed in } 2001 \text {. As- } \\
\text { sumed plausible scenario for mid-century (ca. 2050). }\end{array}$ \\
\hline
\end{tabular}

AMPDry1.89

Modified from observed 2001 precipitation - similar to AMPDry1.43, except that the large magnitude rainfall event 25-September was removed; daily values otherwise multiplied by 1.89. Assumed plausible scenario for late-century (ca. 2100).

Day-neutral strawberries (Jewel variety) were purchased bare root, and planted into containers measuring $12.7 \mathrm{~cm}$ (5 inches) x $12.7 \mathrm{~cm}$ (5 inches) square, $30.48 \mathrm{~cm}$ (12 inches) depth. Soil media used for potting was Pro-Mix BX Original. Between precipitation simulations, plants were stored inside a greenhouse made of $8 \mathrm{~mm}$ clear twinwall polycarbonate paneling (roof, sidewalls, and endwalls) measuring $14.78 \mathrm{~m}$ (48.5 feet) x $5.79 \mathrm{~m}$ (19 feet). The greenhouse was ventilated with horizontal air flow fans. Data collection occurred between 19-May and 30-September, 2021. A variety of variables were measured in order to assess strawberry plant physiological responses to the four precipitation treatments.

\subsection{Volumetric water content, soil temperature, leachate, and nitrate-leachate concentration}

Soil volumetric water content and soil temperature in each pot were measured on a weekly basis using a TDR soil moisture meter (TDR 150, Spectrum Technologies Inc. Aurora, IL). Average values were calculated for each treatment across all pots. Free draining lysimeters were constructed under each treatment block (8 plants each), with 2 replications per treatment (16 plants per treatment). Leachate was collected after every simulated rainfall event. Total volume of leachate was recorded $(\mathrm{mL})$ for each replicate, and subsamples were stored at $40^{\circ} \mathrm{F}$. Subsamples collected within a one-week period were combined, and tested for nitrate concentration (colorimetric analysis) by the University of Maine Soil Testing and Analytical Lab. Not all strawberry plants survived the season, but pots containing dead plants were included in volumetric water content, soil temperature, leachate, and nitrate-leachate concentration measurements until the conclusion of the experiment.

\subsection{Disease}

Plants were inspected for visual evidence of symptoms at the end of the experiment. Specifically, the percentage of leaf area with leaf spots on each plant were recorded, and averaged across all plants within a treatment. At the conclusion of the experiment, crown and root diseases were assessed through destructive sampling of the remaining living plants. During this process, two pieces of roots and two pieces of crown from each plant 
were cut and sterilized with a $10 \%$ bleach solution for one minute and then rinsed in sterile, deionized water. The plant material was then plated in water agar fungal media and incubated at $25^{\circ} \mathrm{C}$ for one week. Agar plates were viewed under a compound microscope (Olympus BX5) and assessed for fungal diseases, which were morphologically identified if present. When a pathogen was identified from a plant piece, a percentage was generated with $100 \%$ representing all four of the plated plant pieces having fungal growth. Foliage showing symptomatic leaf spots were selected and placed in a moist chamber that was also incubated at $25^{\circ} \mathrm{C}$ for one week. After incubation, foliage was viewed under a dissecting microscope (Olympus SZX16) to determine the presence and absence of pathogenic fungal growth.

\subsection{Leaf chlorophyll fluorescence and chlorophyll concentration}

Leaf photosynthetic performance was assessed through leaf chlorophyll fluorescence measurements. Variables measured included the quantum yield of photosystem II (Y(II)), which equals $\mathrm{Fv} / \mathrm{Fm}$, and is sensitive to stress. We also assessed the electron transport rate (ETR), which indicates actual photosynthetic performance under specific light conditions and is related to photosynthetic CO2 assimilation [30]. Both Y(II) and ETR were measured weekly from 12:00 to 4:00 pm using a FluorPen portable leaf fluorescence meter (Photon Systems Instruments, Drásov, Czech Republic). Additionally, we assessed leaf chlorophyll concentration, which has been shown to be strongly related to nitrogen $(\mathrm{N})$ concentration of mature leaves. It is expected that there is a strong correlation between chlorophyll concentration and photosynthetic rate. Leaf chlorophyll concentration Soil Plant Analysis Development (SPAD) measurements were made weekly using a hand-held chlorophyll meter (SPAD 502; Minolta Corp., Osaka, Japan), an evidence-based approach to assessing plant $\mathrm{N}$ status [31]. All measurements related to photosynthetic potential and performance, and chlorophyll concentration were made on a weekly basis from individual plants (one leaf per plant).

\subsection{Biomass}

Above and below ground biomass samples were collected as the strawberry plants died over the course of the experiment, and at the end of experiment. Above ground biomass assessment methods established by the United States Department of Agriculture (USDA) Natural Resources Conservation Service [32,33] were used in this assessment. Specifically, all vegetation was clipped at the soil surface, and stored prior to processing. Samples were weighed prior to being oven dried at $60^{\circ} \mathrm{C}$, and subsequently reweighed. To assess below ground biomass, all soil was removed from the plant roots and processed using the same approach as above ground biomass samples.

\subsection{Analysis}

To assess the overall seasonal effects of precipitation treatments on our various, normally distributed dependent variables, we performed a series of one-way analysis of variance (ANOVA) tests with Tukey HSD post-hoc tests. For those variables that did not meet assumptions of normality, non-parametric Kruskal Wallis rank sums tests followed with Pairwise Wilcoxon Ranked Sum comparisons were employed. To better assess the effects of seasonal precipitation distribution of precipitation on relevant dependent variables, a series of generalized linear regression models (GLMs) with gamma distributions and inverse link functions were used. This approach was chosen because we assumed a fixed relationship between the mean values of each model and the variance, as all readings are always greater than zero with non-normal, skewed distributions [34,35]. Gamma distributions are often utilized in description of precipitation data [36], and can be interpreted using both transformed and original scales [37]. All analyses included in this manuscript were performed using R Version 4.1.0 [38], and plots created using ggplot2 [39]. 


\section{Results}

3.1. Volumetric water content, soil temperature, leachate, and nitrate-leachate concentration

Figure 2 shows simulated precipitation amounts $(\mathrm{cm})$ per week, soil volumetric water content (\%), and soil temperature (degrees Celsius) by treatment. As expected, precipitation amounts applied through the rainfall simulator were associated with differences in volumetric water content, though the difference between treatments was not as great as expected (see table 2 for model results). Likewise, there was little difference between treatments and their effect on soil temperature. The use of commercial potting media with excellent drainage may have influenced these results. This suggests that, unless extreme rainfall events occur, well drained soils are unlikely to demonstrate highly variable responses in $\mathrm{kPa}$ or degrees $\mathrm{C}$.

It should be noted that not all plants survived the experiment: In RECDry, 9 plants died between weeks 5 and 9 (56\% of plants in this treatment); in RECWet, 1 plant died by week 10 (6\%); in AMPDry1.43, 1 plant died by week 1 (6\%), and in AMPDry1.89, 2 plants died by week 10 (13\%). Not all plant death was attributable to the experimental design, however. Planting stock failure was the cause of early plant mortality. 


\section{A Preciptation}

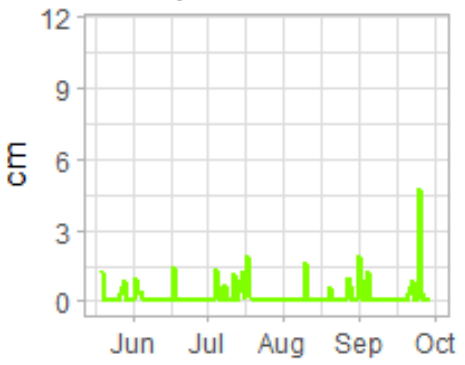

B

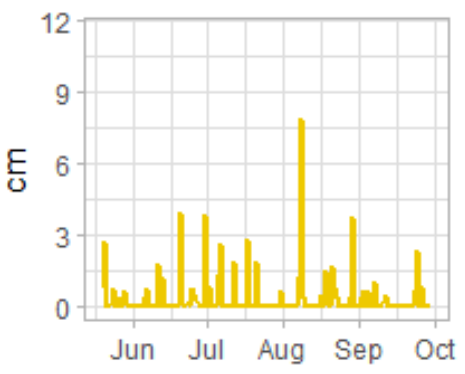

C

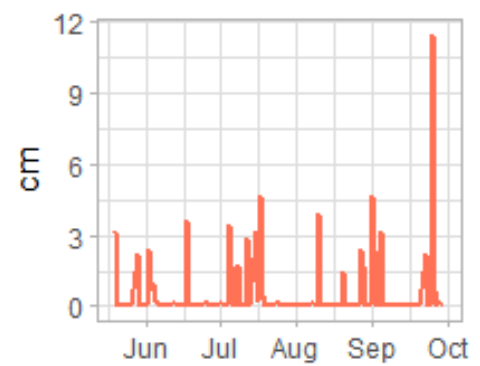

D

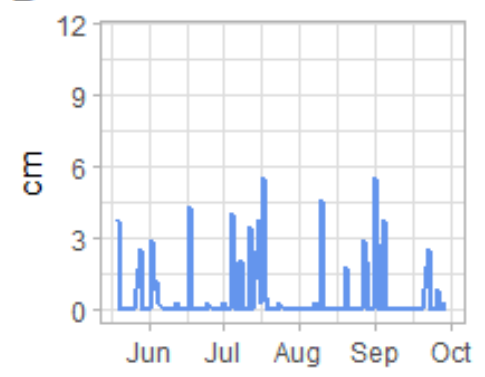

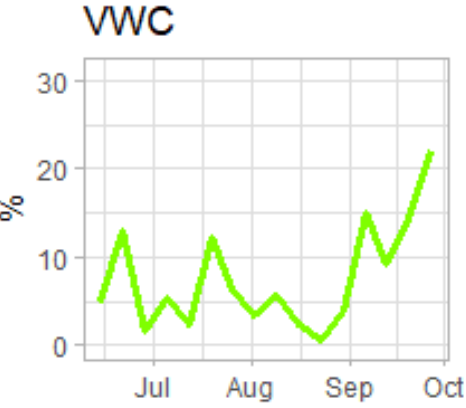
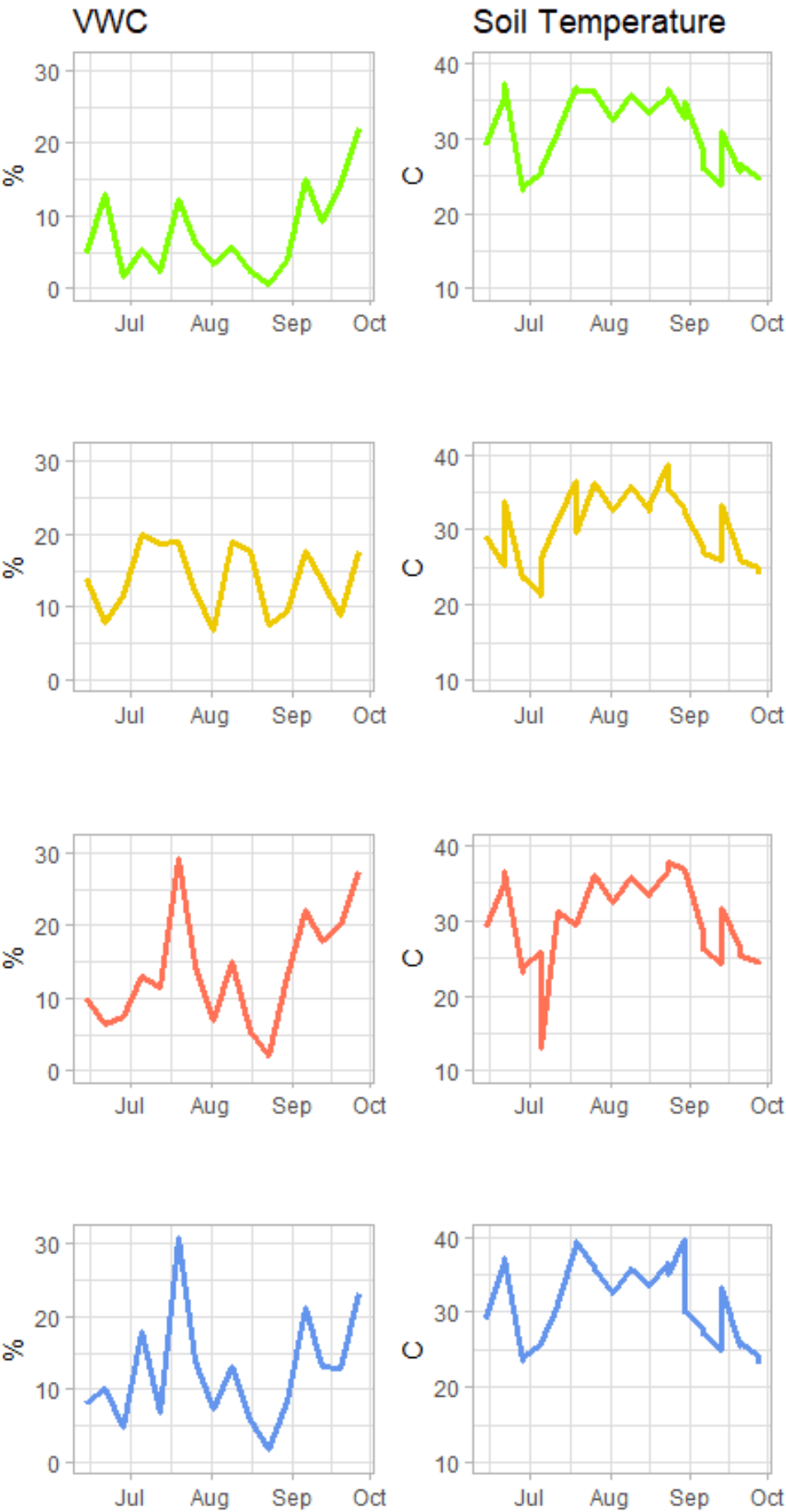

Figure 2. Recorded simulated precipitation $(\mathrm{cm})$, soil volumetric water content (VWC, \%), and soil temperature (degrees Celsius) in each treatment: $\mathrm{A}=$ RECDry, B = RECWet, $\mathrm{C}=\mathrm{AMPDry} 1.43, \mathrm{D}=$ AMPDry1.89). Note that VWC and soil temperature measurements did not commence until July 2021. 
Table 2: Estimated regression parameters, standard errors, coefficients, and p-values for 2 gamma GLMs.

\begin{tabular}{lccccc}
\hline \multicolumn{5}{c}{ Model 1: Soil moisture (kPa, measured weekly) } \\
\hline Estimate $(\beta)$ & Standard Error & $\mathrm{t}$-value & $\mathrm{p}$-value & $\mathrm{CI}(2.5 \% ; 97.5 \%)$ \\
\hline RECDry & 0.111 & 0.007 & 14.95 & $<0.001^{* * *}$ & $0.098 ; 0.127$ \\
AMPDry1.43 & 0.073 & 0.005 & 15.81 & $<0.001^{* * *}$ & $0.063 ; 0.080$ \\
AMPDry1.89 & 0.065 & 0.004 & 15.65 & $<0.001^{* * *}$ & $0.058 ; 0.074$ \\
Dit & 0.073 & 0.005 & 15.81 & $<0.001^{* * *}$ & $0.064 ; 0.083$
\end{tabular}

Dispersion parameter $=0.416 ;$ null deviance $=\mathrm{NaN}$ on 398 degrees of freedom; residual deviance $=191.47$ on 394 degrees of freedom; $A I C=2,718.9$; Number of Fisher Scoring iterations $=6 ; R 2=0.047$. Note that $k P a=0$ indicates soil-water saturation, and dryness increases as $\mathrm{kPa}$ increases.

\begin{tabular}{lccccc}
\hline \multicolumn{7}{c}{ Model 2: Soil temperature (measured weekly) } \\
\hline RECDry & Estimate $(\beta)$ & Standard Error & $\mathrm{t}$-value & $\mathrm{p}$-value & $\mathrm{CI}(2.5 \% ; 97.5 \%)$ \\
RECWet & 0.032 & 0.001 & 34.16 & $<0.0011^{* * *}$ & $0.031 ; 0.034$ \\
AMPDry1.43 & 0.033 & 0.001 & 34.16 & $<0.0011^{* * *}$ & $0.031 ; 0.035$ \\
AMPDry1.89 & 0.033 & 0.001 & 34.16 & $<0.0011^{* * *}$ & $0.031 ; 0.035$ \\
Di* & 0.032 & 0.001 & 34.16 & $<0.0011^{* * *}$ & $0.030 ; 0.034$
\end{tabular}

Dispersion parameter $=0.027$; null deviance $=\mathrm{NaN}$ on 128 degrees of freedom; residual deviance $=3.712$ on 124 degrees of freedom; $A I C=793.79 ;$ Number of Fisher Scoring iterations $=4 ; R 2=-0.026$.

To assess total water loss through leaching, we recorded the total volume of water collected in modified pan lysimeters from each treatment. An ANOVA showed statistically significant differences overall $(\mathrm{F}=6.846 \mathrm{df}=3, \mathrm{p}<0.000)$, and post-hoc (Tukey HSD) tests suggested differences between all treatments except AMPDry1.43 and RecWet, which reflects the similar total precipitation amounts applied in these two scenarios. Nitrate-in-leachate (N-leachate) concentrations were low in all samples, between $0.014 \mathrm{mg} / \mathrm{L}$ and $0.628 \mathrm{mg} / \mathrm{L}$ (figure 3). Differences in the actual rate of N-leachate between treatments were determined using a Kruskal Wallis rank sums test $(\mathrm{H}=13.73, \mathrm{df}=3, \mathrm{p}=0.003)$. While there were statistical differences observed between RECDry and all other treatments, there was no statistical difference observed among other treatments.
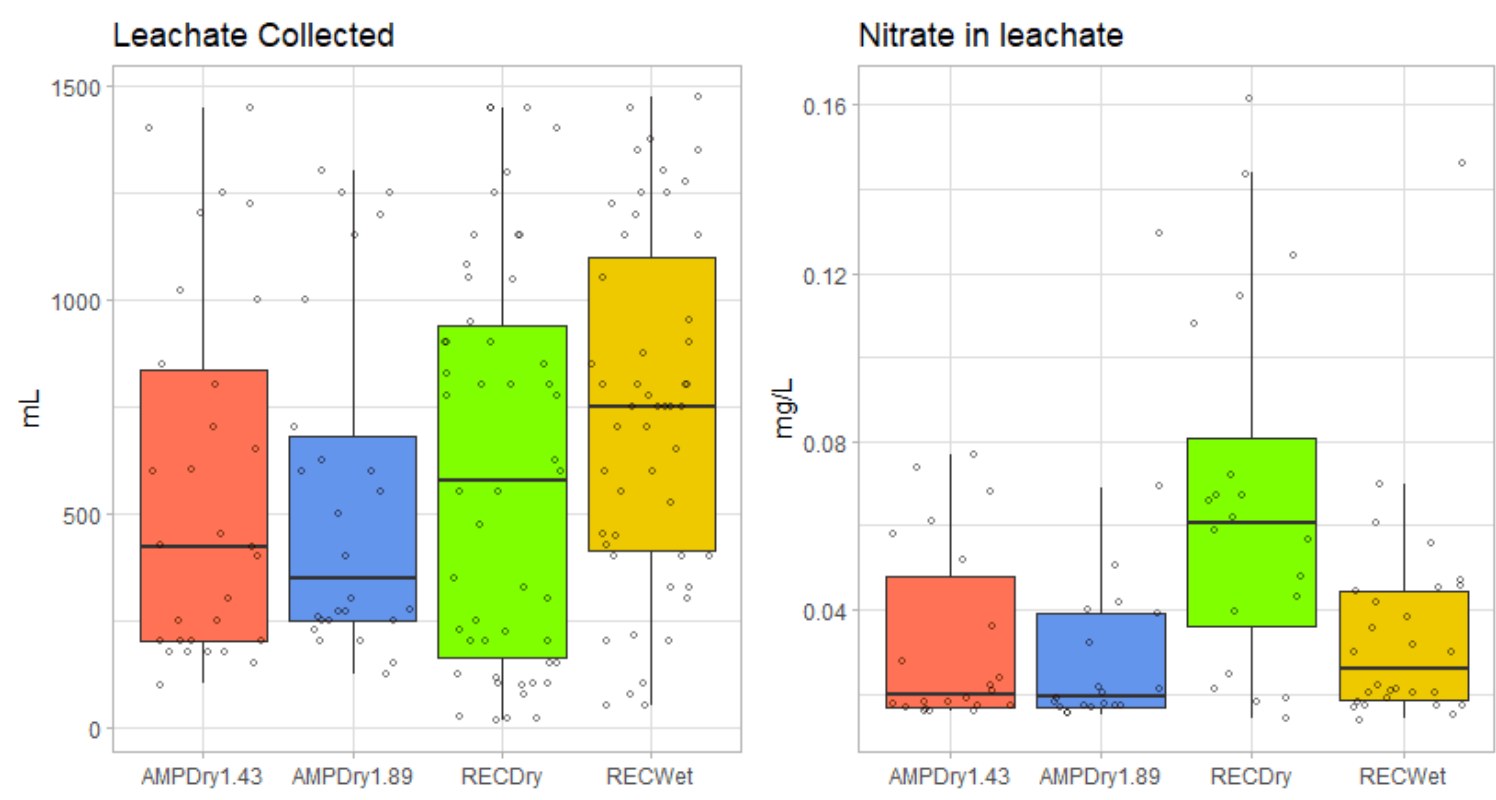

Figure 3. Seasonal differences in total leachate $(\mathrm{mL})$ collected and concentration of nitrate in leachate $(\mathrm{N}$-leachate) $(\mathrm{mg} / \mathrm{L})$ by treatment across the experimental period. 
Model results (table 3) show that the precipitation treatments influence the N-leachate $(\mathrm{mg} / \mathrm{L})$ on a weekly basis. Notably, treatments designed to simulate future conditions had higher seasonal, and often weekly, precipitation totals with uneven seasonal distribution (AMPDry1.43, and AMPDry1.89). These treatments were more likely to have higher N-leachate concentrations than treatments designed to simulate current conditions, including the lowest precipitation treatment (RECDry) and the only treatment with even seasonal distribution (RECWet). This suggests that more $\mathrm{N}$ is lost from soil media when precipitation increases on a weekly basis, and is unevenly distributed across the growing season. It should also be noted that no additional $\mathrm{N}$ was provided to the plants beyond what was included in the soil media, and additional applications may have led to more noticeable differences between treatments. This should be further explored in future research.

In regards to leachate amounts, our models diverged from the findings of the ANOVA and Tukey HSD tests described above. Specifically, the leachate model suggested minimal difference between treatments and the amount of weekly leachate collected, and a poor model fit over all. This suggests that collecting weekly leachate amounts is a less useful measure than assessing total leachate over the course of a growing season. Our results were likely influenced by the practice of collecting leachate data after plants had died (in weeks 5-9), which may have led to superficially high rates of leachate drainage in plots without living tissue.

Table 3: Estimated regression parameters, standard errors, coefficients, and p-values for 2 gamma GLMs.

\begin{tabular}{|c|c|c|c|c|c|}
\hline \multicolumn{6}{|c|}{ Model 3: N-leachate (collected weekly, mg/L) } \\
\hline & Estimate $(\beta)$ & Standard Error & t-value & p-value & CI $(2.5 \% ; 97.5 \%)$ \\
\hline RECDry & 10.720 & 10.720 & 10.720 & 10.720 & 10.720 \\
\hline RECWet & 2.208 & 2.208 & 2.208 & 2.208 & 2.208 \\
\hline AMPDry1.43 & 4.855 & 4.855 & 4.855 & 4.855 & 4.855 \\
\hline AMPDry1.89 & $<0.001^{* * *}$ & $<0.001^{* * *}$ & $<0.001^{* * *}$ & $<0.001^{* * *}$ & $<0.001^{* * *}$ \\
\hline \multicolumn{6}{|c|}{$\begin{array}{l}\text { Dispersion parameter }=0.866 ; \text { null deviance }=\text { NaN on } 91 \text { degrees of freedom; residual deviance }=44.913 \text { on } 87 \text { degrees of freedom; AIC } \\
=-409.81 ; \text { number of Fisher Scoring iterations }=7 ; \text { adjusted } R 2=0.075\end{array}$} \\
\hline \multicolumn{6}{|c|}{ Model 4: Leachate (collected at each precipitation event, $\mathrm{mL}$ ) } \\
\hline & Estimate $(\beta)$ & Standard Error & t-value & $\mathrm{p}$-value & $\mathrm{CI}(2.5 \% ; 97.5 \%)$ \\
\hline RECDry & 0.001 & 0.001 & 0.001 & 0.001 & 0.001 \\
\hline RECWet & 0.001 & 0.001 & 0.001 & 0.001 & 0.001 \\
\hline AMPDry1.43 & 5.415 & 5.415 & 5.415 & 5.415 & 5.415 \\
\hline AMPDry1.89 & $<0.001^{* * *}$ & $<0.001^{* * *}$ & $<0.001^{* * *}$ & $<0.001^{* * *}$ & $<0.001^{* * *}$ \\
\hline
\end{tabular}

\subsection{Disease}

Visual inspections of leaf tissue were conducted in the last week of the experiment (on September 28, 2021). Leaf spots were typical of late season strawberry plantings, meaning that all treatments had some evidence of leaf spot: RECwet averaged 3\% leaf coverage, RECdry averaged 3\%, AMPdry1.43 averaged 2\%, and AMPdry1.89 averaged $1 \%$. Symptomatic foliage was incubated for one week, after which two pathogens were observed: Neopestalotiopsis sp. and Alternaria sp. in the RECDry and AMPDry1.89 treatments. Notably, neither pathogens were observed on foliage in the RECWet and AMPDry1.43 treatments.

Roots and the crown of each plant were sampled and tested for the presents of fungal pathogens by plating in water agar plates. The pathogens Pythium sp., Rhizoctonia sp., 
and Fusarium sp. were found in each treatment in similar amounts (no differences between treatments). When processing plants for disease assessment, crown discoloration was noted on the majority of the plants in the RECWet (11 out of 15 plants) and AMPDry1.89 (five of 14 plants) treatments, but not on the RECDry or AMPDry1.43 treatments.

\subsection{Leaf chlorophyll fluorescence and chlorophyll concentration}

Photosynthetic potential and performance were assessed through leaf chlorophyll fluorescence. A Kruskal Wallis rank sums test indicated no significant difference in Y(II) between treatments $(\mathrm{H}=3.582, \mathrm{df}=3, \mathrm{p}=0.3103)$. A Kruskal Wallis rank sums test was also used to assess difference in the electron transport rate (ETR), or photosynthetic performance, across treatments $(\mathrm{H}=14.163, \mathrm{df}=3, \mathrm{p}=0.002)$. Pairwise Wilcoxon Ranked Sum comparisons showed significant differences between AMPDry1.43 and all other treatments, but otherwise no differences between treatments (figure 4). Chlorophyll concentration was assessed using SPAD readings, or the difference between the transmittance of red light and infrared light (both measured in nanometers). An ANOVA showed statistically significant differences across treatments $(\mathrm{F}=23.16 \mathrm{df}=3, \mathrm{p}<0.000)$, and post-hoc (Tukey HSD) tests suggested differences between all treatments $(p<0.01)$ with the exception of between AMPDry1.43 and AMPdry1.89. 


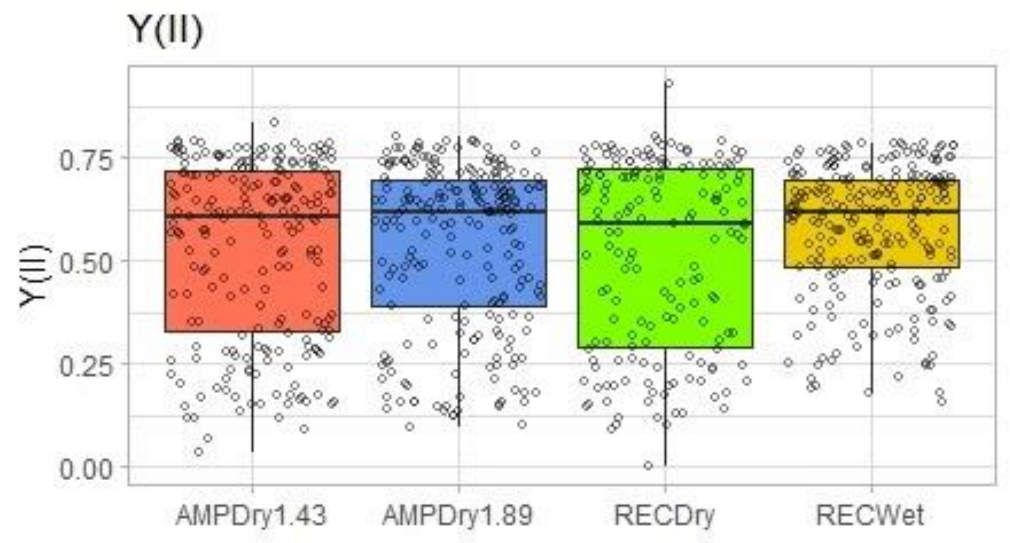

\section{Electron Transport Rate}

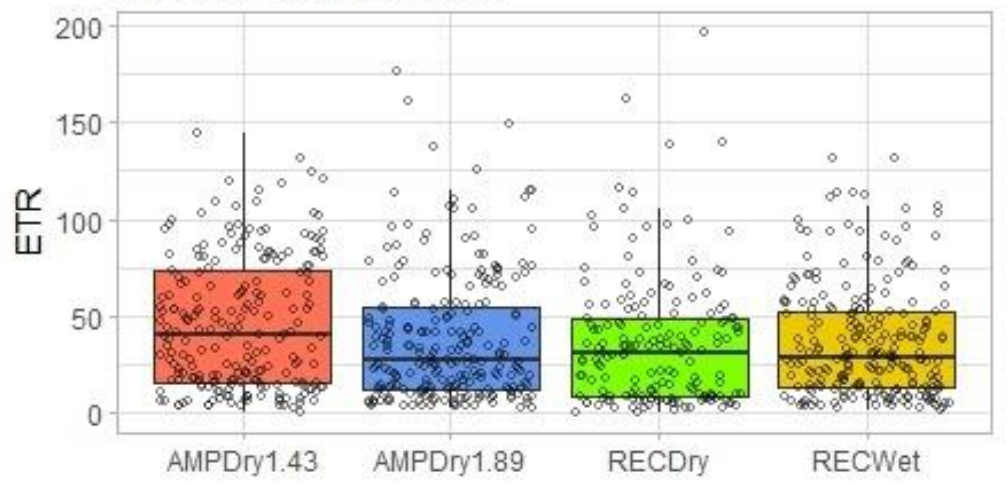

\section{Chlorophyll Content}

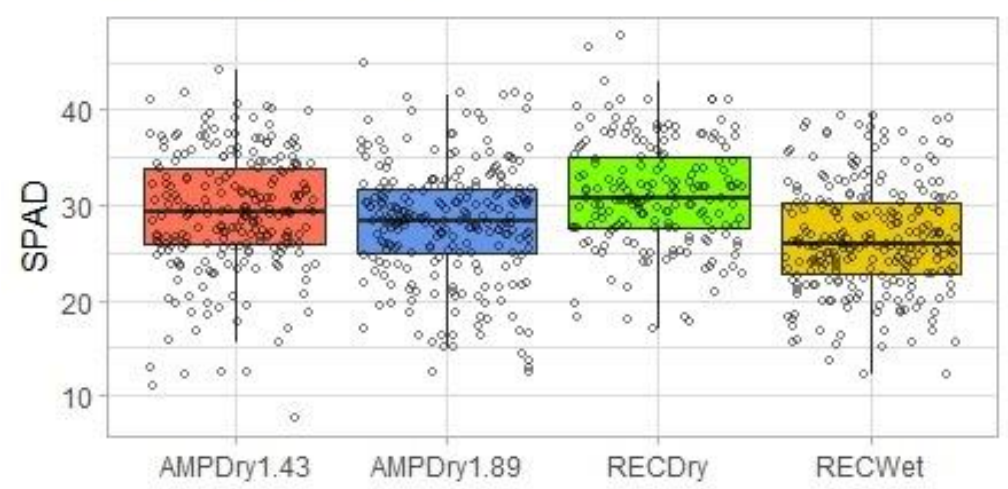

Figure 4. Differences in the quantum yield of photosystem II (Y(II)), photosynthetic electron transport rate (ETR), and chlorophyll concentration of leaves (SPAD unit), assessed by treatment across the experimental period.

This suggests that the amount of rainfall in any given precipitation event is less important than the distribution of precipitation across time, when examining the effects of rainfall on photosynthetic potential, performance, and chlorophyll content. However, three GLM model results (table 3) showed little difference in Y(II) or ETR, with a slightly higher chance that $Y(\mathrm{II})$ and ETR rates will be higher in drier conditions. It should be noted that Y(II) remained fairly constant throughout the season across treatments, while ETR trended slightly down (figure 5). Additionally, little difference was observed between treatments in terms of their effects in chlorophyll concentration (SPAD), which is related to $\mathrm{N}$ accumulation in leaves. Chlorophyll concentration trended slightly higher towards the end of the experimental period. 
Table 4: Estimated regression parameters, standard errors, coefficients, and p-values for 3 gamma GLMs.

\begin{tabular}{cccccc}
\hline \multicolumn{5}{c}{ Model 5: Y(II) measured weekly } \\
\hline RECDry & Estimate $(\beta)$ & Standard Error & t-value & p-value & CI $(2.5 \% ; 97.5 \%)$ \\
\hline RECWet & 1.937 & 0.057 & 34.33 & $<0.001^{* * *}$ & $1.829 ; 2.050$ \\
AMPDry1.43 & 1.734 & 0.043 & 40.44 & $<0.001^{* * *}$ & $1.652 ; 1.820$ \\
AMPDry1.89 & 1.893 & 0.048 & 39.19 & $<0.001^{* * *}$ & $1.800 ; 2.000$ \\
& 1.863 & 0.046 & 40.17 & $<0.001^{* * *}$ & $1.774 ; 1.955$
\end{tabular}

Dispersion parameter $=0.140 ;$ null deviance $=\mathrm{NaN}$ on 835 degrees of freedom; residual deviance $=170.48$ on 831 degrees of freedom; AIC =-115.11; Number of Fisher Scoring iterations $=5$; adjusted $R 2=0.004$.

\begin{tabular}{lccccc}
\hline \multicolumn{5}{c}{ Model 6: ETR measured weekly } \\
\hline RECDry & Estimate $(\beta)$ & Standard Error & t-value & p-value & CI $(2.5 \% ; 97.5 \%)$ \\
RECWet & 0.030 & 0.002 & 15.69 & $<0.001 * * *$ & $0.024 ; 0.030$ \\
AMPDry1.43 & 0.027 & 0.001 & 18.48 & $<0.001$ *** & $0.025 ; 0.030$ \\
AMPDry1.89 & 0.022 & 0.001 & 17.91 & $<0.001^{* * *}$ & $0.019 ; 0.024$ \\
& 0.026 & 0.001 & 18.48 & $<0.001 * * *$ & $0.023 ; 0.029$
\end{tabular}

Dispersion parameter $=0.671 ;$ null deviance $=\mathrm{NaN}$ on 835 degrees of freedom; residual deviance $=656.95$ on 831 degrees of freedom; AIC $=7,758.5$; Number of Fisher Scoring iterations $=6$; adjusted $R 2=0.006$.

Model 7: Chlorophyll concentration (SPAD) measured weekly

\begin{tabular}{lccccc}
\hline & Estimate $(\beta)$ & Standard Error & t-value & p-value & CI $(2.5 \% ; 97.5 \%)$ \\
\hline RECDry & 0.032 & 0.001 & 60.73 & $<0.001^{* * *}$ & $0.032 ; 0.034$ \\
RECWet & 0.038 & 0.001 & 70.80 & $<0.001 * * *$ & $0.038 ; 0.040$ \\
AMPDry1.43 & 0.035 & 0.001 & 68.61 & $<0.001 * * *$ & $0.035 ; 0.037$ \\
AMPDry1.89 & 0.036 & 0.001 & 70.80 & $<0.001 * * *$ & $0.038 ; 0.040$
\end{tabular}

Dispersion parameter $=0.671 ;$ null deviance $=\mathrm{NaN}$ on 835 degrees of freedom; residual deviance $=656.95$ on 831 degrees of freedom; AIC $=7,758.5 ;$ Number of Fisher Scoring iterations $=6$; adjusted $R 2=0.006$. 

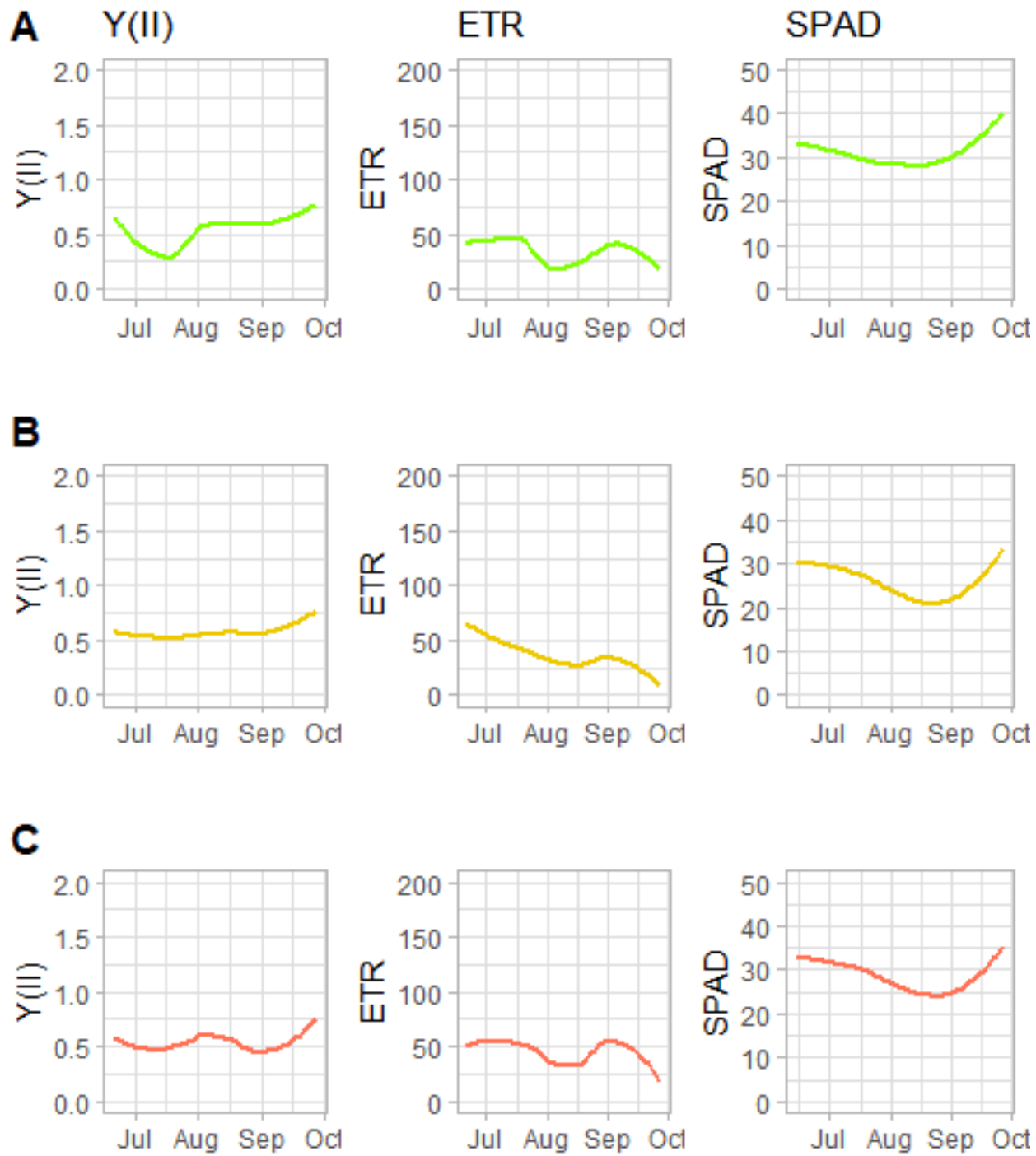

D
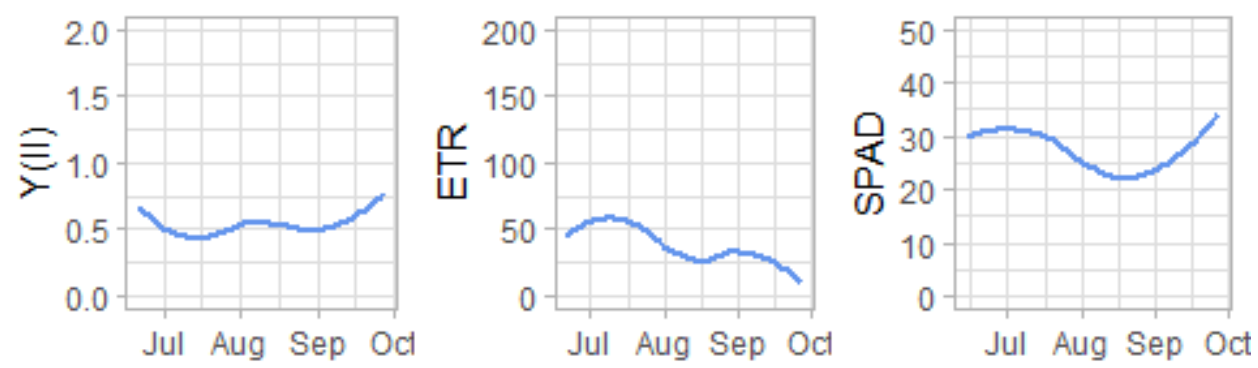

Figure 5: Recorded temporal dynamics in quantum yield of photosystem II (YII), electron transport rate (ETR), and chlorophyll concentration (SPAD) in each treatment: $\mathrm{A}=\mathrm{RECDry}, \mathrm{B}=$

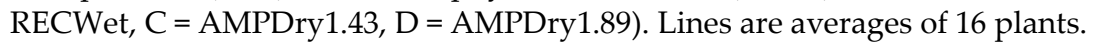

\subsection{Biomass}


Differences in biomass between treatments was assessed at the conclusion of the experiment, with analysis conducted of plant leaves, plant roots, and total biomass. An ANOVA test demonstrated that significant differences in leaf biomasses were evident ( $F$ $=3.006, \mathrm{df}=3, \mathrm{p}=0.04)$, though post-hoc (Tukey HSD) tests suggested that the only statistically significant differences were found between RECDry and AMPDry1.43 treatments. This suggests that the total amount of water received throughout the growing season is a more important driver of leaf biomass, compared to the seasonal distribution of water. Similarly, we performed an ANOVA test on root biomass, finding again that significant differences were evident between treatments $(\mathrm{F}=11.35, \mathrm{df}=3, \mathrm{p}<0.000)$. Post-hoc (Tukey HSD) tests revealed significant differences (adjusted $\mathrm{p}<0.01$ ) between several treatments (figure 6). Differences existed primarily between the precipitation treatments designed to represent current conditions (the REC treatments) and those designed to represent future conditions (the AMP treatments), with root biomass being lower in the current condition scenarios. This suggests that the interaction between changing distribution and seasonal total amounts of precipitation is likely to be an important driver of increased root biomass development in the future.
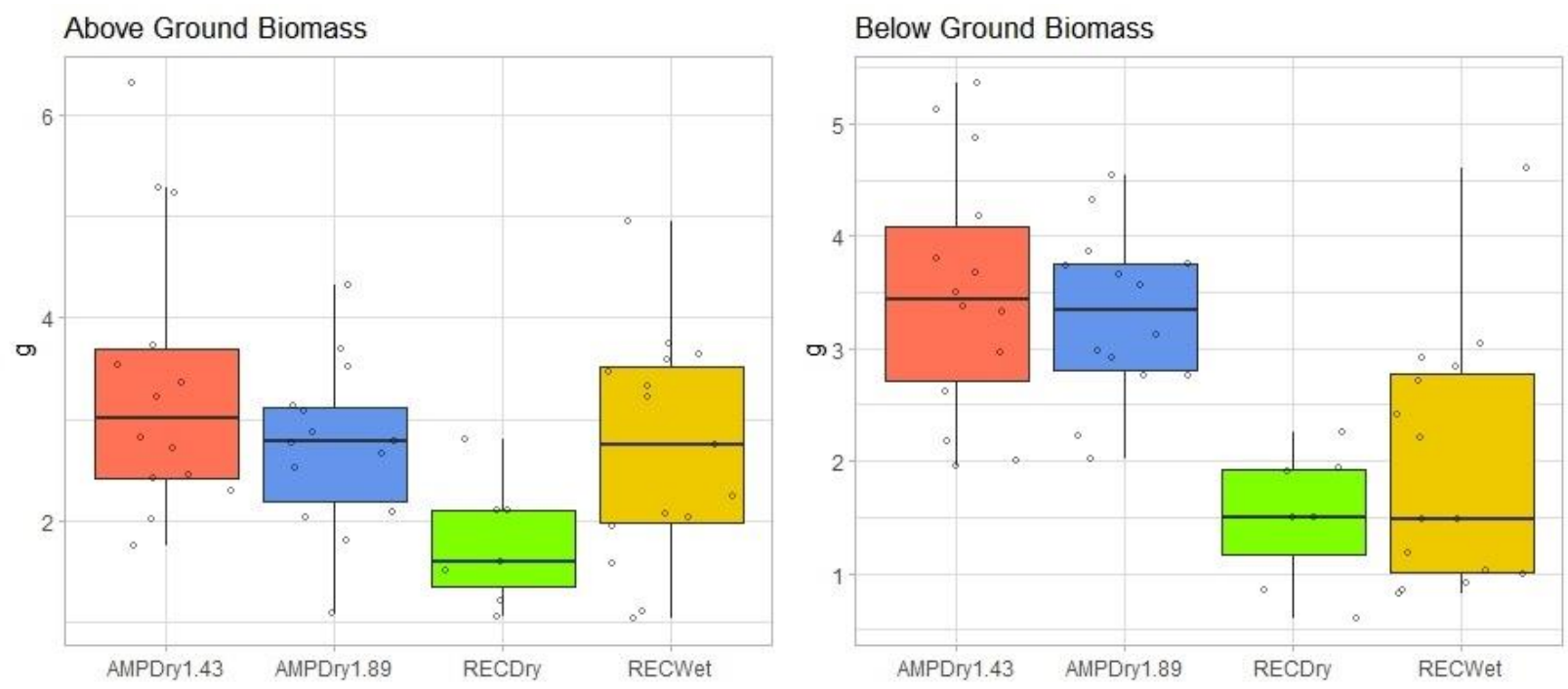

Figure 6: Differences in above and below ground biomass (g), assessed by treatment at the end of the experimental period.

\section{Discussion}

In this study, we identified four important findings. First, we found that leachate amounts did not differ significantly regardless of precipitation amount and distribution across the season. The soil-water capacity of the potting media used in this experiment likely buffered the effects of the precipitation simulation treatments to some degree. Potting media typically has a standardized total porosity of $\geqq 50 \%$ (target air filled porosity $\geqq 10 \%$ and target water-holding capacity $\geqq 40 \%$ ) [40]. It is possible that treatments received simulated precipitation in amounts that did not exceed the field capacity of the potting mix, meaning that the drainable porosity of the soil was not notably different.

Of greater importance is the relationship between N-leachate and total leachate. Our results showed this relationship that was not straightforward, but in alignment with the few field-based trials that address this topic. One such study assessed the effects of rainfall intensification on $\mathrm{N}$-cycling in temperate, agricultural soils. This work showed that while percolation may change depending on rainfall intensity, $\mathrm{N}$-transformations differ depending on moderating factors such as tillage practices [41]. In our study, higher precipitation amounts unevenly distributed across the growing season (in the AMPDry treatments) were more likely to be associated with elevated N-leachate, despite the higher 
survival rate of experimental plants in the AMPDry treatments (and assumed higher $\mathrm{N}$ use by those plants). This supports past findings from experiments in arid and semi-arid environments, where $\mathrm{N}$ accumulates during extended dry periods and is then rapidly released during the microbial processes that follow subsequent precipitation events [42]. For example, large pulses of precipitation have been shown to be associated with higher rates of $\mathrm{N}$ losses through denitrification in Argentina [43]. While the degree to which these dynamics affect $\mathrm{N}$-release in temperate climates was previously uncertain, our study suggests similar dynamics are at play in temperate and arid climates albeit to different degrees. Our findings are also corroborated by studies pointing towards altered soil moisture following intense precipitation events in temperate cropping systems (in the Midwest United States), specifically suggesting changes in N-mobilization following heavy rainfall events [41,44] especially if those rainfall events follow significant droughts [45].

Second, neither total precipitation amount or seasonable distribution were associated with foliar or root disease pressure. Similar degrees of damage from disease were observed across all treatments at the end of the experimental period. Most studies looking at water stress have been focused on water deficit due to the effect of climate change in the region of study rather than an over abundance of water. Even with water deficits, a pathogen's effect on a plant is specific to the pathogen being studied. This was observed in inoculated grapes undergoing water stress that showed no significant difference between well-watered vines compared to those undergoing water deficit, while a different pathogen in the same study showed a significant increase in colonization of the vines in the well-watered treatment [46]. Additionally, biotrophic pathogens have been shown to be less severe in strawberries that have gone through a water deficit [47]. Since we evaluated all diseases present, it is possible the diseases we did observe are not affected favorably or negatively to the treatments we carried out. It is also possible there was no difference between our treatments because the plants were not inoculated and were potted (no movement of soilborne diseases to move from one plant to the next) and were protected in a greenhouse (limiting exposure to wind-dispersed spores). Additionally, we expected to observe endemic examples of red stele (Phytophthora fragariae), a common fungal disease that affects strawberry roots. However, this relied on the plants already being diseased at the time of planting, which was not the case.

Third, this study demonstrated that changing precipitation amounts and distribution across the growing season in this study may have a small effect on leaf photosynthesis, with drier conditions being associated with slightly higher Y(II) and ETR rates. This finding is supported by prior studies, which showed that while drought affects strawberry plants' leaf water potential, fresh and dry mass, leaf area, and leaf number, it does not appear to affect $Y($ II) significantly and therefore may not be the best indicator of drought resistance [48]. Other research, however, demonstrates that drought stress in fruit crops leads to down-regulation of photosynthesis, with severe drought conditions decreasing the degree of correlation between fluorescence and photosynthetic performance [49]. Recovery from drought conditions can occur within 24-hours, depending on the crop and the severity of the drought conditions [50]. Our findings support this, and we suggest that distribution of precipitation across time (which captures extended dry periods and drought conditions) has more influence on photosynthetic capacity and performance than the intensity of any one precipitation event. Additionally, while our study did not support the assumption that chlorophyll content in strawberries was affected by different precipitation treatments, prior research has suggested that severe drought leads to reduced chlorophyll concentration, and that chlorophyll concentration recovers more slowly from drought than does photosynthetic capacity [51]. It is likely that our study did not align with this prior work due to the limited degree of drought introduced through our treatments, and that more severe drying would yield different results. Indeed, no long-term stress was detected in strawberry plants under all the treatments, demonstrated by the fact that Y(II) remained fairly constant throughout the period of treatments (i.e. there was no reduction in quantum yield of photosystem II due to treatments). 
Lastly, our results suggest that the total amount of water received throughout the growing season is a more important driver of leaf biomass than the seasonal distribution of water. The interaction between changing distribution and seasonal total amounts of precipitation is likely to be an important driver of increased root biomass development in the future. It has long been known that root development in strawberries follows periods of carbohydrate accumulation [52], which is facilitated by sufficient levels of crop-available water. More robust roots are associated with better access to both crop water-use efficiency and uptake of soil-immobile nutrients [53]. However, it is noted that strawberry cultivars can vary significantly when it comes to their tolerance to water deficits [3,54]. Cultivars exhibiting high rates of water use efficiency, are more likely to have higher leaf biomass [54]. Additionally, prior research suggests that the canopy structure of strawberries is influenced by sustained drought conditions over time, and that total aerial biomass may be less important for drought resistance than canopy structure and leaf orientation, and osmotic adjustments [55].

\section{Conclusion}

Understanding crop responses to current and future precipitation scenarios requires a systems approach. Through a simulated precipitation experiment in potted strawberries, we observed that probably future precipitation conditions in the Northeastern United States may lead to increased N-leachate concentrations, implying that producers may need to invest in new approaches that both increase the efficiency of fertilizer applications while minimizing leaching of nitrate into ground and surface water. It is likely that precipitation variability across the growing season will stress unirrigated crops in future decades, and that without attentive irrigation applications these crops will suffer reduced photosynthetic performance, and by extension yield and quality. Further, projected climate warming in the future will also increase the risk of drought stress due to increased crop and soil water loss (evapotranspiration) [56]. Lastly, we found that leaf biomass is likely more affected by total precipitation than seasonal distribution, but the interaction between changing distribution and seasonal total amounts of precipitation is likely to be an important driver of increased root biomass development. As strawberries and other small fruits require different increased water during specific growth periods (i.e. fruit set), distribution of precipitation has implications for yield and fruit quality especially in agroecological systems without supplemental irrigation. The interactions between water availability, changing precipitation patterns, and plant physiology, has implications for strawberry production specifically, but also points towards the need to better understand how changing precipitation will alter agroecosystems in temperate climates. Climate adaptive management will likely require commercial producers to alter water, soil, crop health, and fertility management if sustainable production is to be a priority in the future.

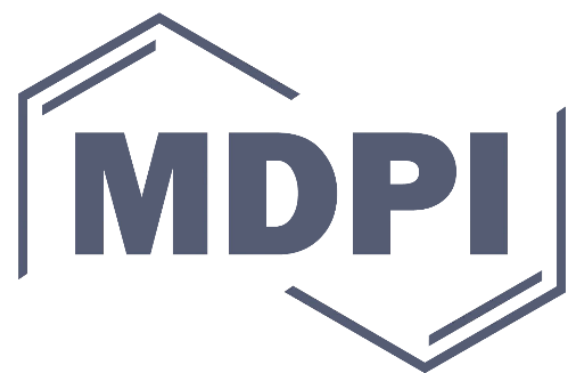

Author Contributions: Conceptualization, RES, YZ, SB, AS; methodology, RES, HJ, YJZ, SB, AS; data collection: HJ, KB, AS; formal analysis, HJ, RES; visualization (except for figure 1), HJ, RES; writing - original draft preparation, RES; writing - review and editing, RES, AS, SB, YJZ; supervision and project administration, RES; funding acquisition, RES, YJZ, AS. All authors have read and agreed to the submitted version of this manuscript.

Funding: This work was supported by the University of Maine Extension, Maine Food and Agriculture Center Integrated Research and Extension Grant program, and the USDA National Institute 
of Food and Agriculture, Hatch Project numbers ME0-1022424 (RES) and ME0-22021 (YJZ) through the Maine Agricultural \& Forest Experiment Station. YJZ was also supported by the UMaine Faculty Summer Research Award. Maine Agricultural and Forest Experiment Publication Number 3870.

Data Availability Statement: The data presented in this study are available from the authors.

Acknowledgments: The authors of this manuscript wish to thank Dr. Brandon Lieberthal, Dr. Scott C. Merrill, and Dr. Meredith T. Niles for their statistical support. Drs. Harry Schomberg and ChiHua Huang of the USDA Agricultural Research Service provided important guidance to our team in the development of the rainfall simulator. Sara Kelemen created figure 1. Sarah Dorey provided onsite research support.

Conflicts of Interest: The authors declare no conflict of interest. The funders had no role in the design of the study; in the collection, analyses, or interpretation of data; in the writing of the manuscript, or in the decision to publish the results.

\section{References}

1. Samtani, J.B.; Rom, C.R.; Friedrich, H.; Fennimore, S.A.; Finn, C.E.; Petran, A.; Wallace, R.W.; Pritts, M.P.; Fernandez, G.; Chase, C.A.; et al. The Status and Future of the Strawberry Industry in the United States. hortte 2019, 29, 11-24, doi:10.21273/HORTTECH04135-18.

2. Palencia, P.; Martínez, F.; Medina, J.J.; López-Medina, J. Strawberry Yield Efficiency and Its Correlation with Temperature and Solar Radiation. Horticultura Brasileira 2013, 31, 93-99, doi:10.1590/S0102-05362013000100015.

3. Ariza, M.T.; Miranda, L.; Gómez-Mora, J.A.; Medina, J.J.; Lozano, D.; Gavilán, P.; Soria, C.; Martínez-Ferri, E. Yield and Fruit Quality of Strawberry Cultivars under Different Irrigation Regimes. Agronomy 2021, 11, 261, doi:10.3390/agronomy11020261.

4. New England Small Fruit Management Guide; Schloemann, S., Garofalo, E., Eds.; 2019th-2020 Edition ed.; University of Massachusetts Extension: Amherst, MA, 2019.

5. Orde, K.; Sideman, B.; Pritts, M.; Demchak, K. Low Tunnel Strawberry Production Guide; University of New Hampshire Cooperative Extension, 2018.

6. IPCC Climate Change 2021: The Physical Science Basis; United Nations Intergovernmental Panel on Climate Change, 2021;

7. Kundzewicz, Z.W.; Mata, L.J.; Arnell, N.W.; Döll, P.; Jimenez, B.; Miller, K.; Oki, T.; Şen, Z.; Shiklomanov, I. The Implications of Projected Climate Change for Freshwater Resources and Their Management. Hydrological Sciences Journal 2008, 53, 3-10, doi:10.1623/hysj.53.1.3.

8. Döll, P. Vulnerability to the Impact of Climate Change on Renewable Groundwater Resources: A Global-Scale Assessment. Environ. Res. Lett. 2009, 4, 035006, doi:10.1088/1748-9326/4/3/035006.

9. Kundzewicz, Z.W.; Döll, P. Will Groundwater Ease Freshwater Stress under Climate Change? Hydrological Sciences Journal 2009, 54, 665-675, doi:10.1623/hysj.54.4.665.

10. Kunkel, K.E.; Stevens, L.E.; Stevens, S.E.; Sun, L.; Janssen, E.; Wuebbles, D.; Rennells, J.; DeGaetano, A.; Dobson, J.G. Regional Climate Trends and Scenarios for the U.S. National Climate Assessment. Part 1. Climate of the Northeast U.S.; Washington, D.C., 2013; pp. 1-87.

11. Huang, H.; Winter, J.M.; Osterberg, E.C.; Horton, R.M.; Beckage, B. Total and Extreme Precipitation Changes over the Northeastern United States. Journal of Hydrometeorology 2017, doi:10.1175/JHM-D-16-0195.1.

12. Easterling, D.R.; Arnold, J.R.; Knutson, T.; Kunkel, K.E.; LeGrande, A.N.; Leung, L.R.; Vose, R.S.; Waliser, D.E.; Wehner, M.F. Ch. 7: Precipitation Change in the United States. Climate Science Special Report: Fourth National Climate Assessment, Volume I; Washington, DC, 2017.

13. Walsh, J.; Wuebbles, D.; Hayhoe, K. Our Changing Climate; Melillo, J., Richmont, T., Yohe, G., Eds.; U.S. Global Change Research Program, 2014; p. 67.

14. Wolfe, D.W.; DeGaetano, A.T.; Peck, G.M.; Carey, M.; Ziska, L.H.; Lea-Cox, J.; Kemanian, A.R.; Hoffmann, M.P.; Hollinger, D.Y. Unique Challenges and Opportunities for Northeastern US Crop Production in a Changing Climate. Climatic Change 2018, 146, 231-245, doi:10.1007/s10584-017-2109-7.

15. Schattman, R.E.; Niles, M.T.; Aitken, H.M. Water Use Governance in a Temperate Region: Implications for Agricultural Climate Change Adaptation in the Northeastern United States. Ambio 2020, 1-14, doi:10.1007/s13280-020-01417-6.

16. Slatyer, R.O. Physiological Significance of Internal Water Relations to Crop Yield. In Physiological Aspects of Crop Yield; Eastin, J.D., Haskins, F.A., Sullivan, C.Y., van Bavel, C.H.M., Eds.; American Society of Agronomy, Crop Science Society of America: Madison, WI, USA, 1969; pp. 53-83 ISBN 978-0-89118-571-0.

17. Palencia, P.; Martínez, F.; Medina-M'inguez, J.; Vázquez, E.; Flores, F.; López-Medina, J. Effects of Climate Change on Strawberry Production. Acta Horticulturae 2009, 838, 51-53, doi:10.17660/ActaHortic.2009.838.6.

18. Barai, K.; Tasnim, R.; Hall, B.; Rahimzadeh-Bajgiran, P.; Zhang, Y.-J. Is Drought Increasing in Maine and Hurting Wild Blueberry Production? Climate 2021, 9, 178, doi:10.3390/cli9120178.

19. Ahmed, S.; Stepp, J.R. Beyond Yields: Climate Change Effects on Specialty Crop Quality and Agroecological Management. Elementa: Science of the Anthropocene 2016, 4, 000092-000092, doi:10.12952/journal.elementa.000092.

20. Kumar, S.; Dey, P. Effects of Different Mulches and Irrigation Methods on Root Growth, Nutrient Uptake, Water-Use Efficiency and Yield of Strawberry. Scientia Horticulturae 2011, 127, 318-324, doi:10.1016/j.scienta.2010.10.023. 
21. May, G.M.; Pritts, M.P.; Kelly, M.J. Seasonal Patterns of Growth and Tissue Nutrient Content in Strawberries. Journal of Plant Nutrition 1994, 17, 1149-1162, doi:10.1080/01904169409364795.

22. Silva-Pérez, V.; De Faveri, J.; Molero, G.; Deery, D.M.; Condon, A.G.; Raynolds, M.P.; Evans, J.R.; Furbank, R.T. Genetic Variation for Photosynthetic Capacity and Efficiency in Spring Wheat. Journal of Experimental Botany 2020, 71, 2299-2311, doi:https://doi.org/10.1093/jxb/erz439.

23. Ghimire, B.; Timsina, D.; Nepal, J. Analysis of Chlorophyll Content and Its Correlation with Yield Attributing Traits on Early Varieties of Maize (Zea Mays L.). Journal of Maize Research and Development 2015, 1, 134-145, doi:10.3126/jmrd.v1i1.14251.

24. Datt, B. A New Reflectance Index for Remote Sensing of Chlorophyll Content in Higher Plants: Tests Using Eucalyptus Leaves. Journal of Plant Physiology 1999, 154, 30-36, doi:10.1016/S0176-1617(99)80314-9.

25. Gitelson, A.A.; Gritz, Y.; Merzlyak, M.N. Relationships between Leaf Chlorophyll Content and Spectral Reflectance and Algorithms for Non-Destructive Chlorophyll Assessment in Higher Plant Leaves. Journal of Plant Physiology 2003, 160, 271-282, doi:10.1078/0176-1617-00887.

26. Yıldırım, M.; Kılıç, H.; Kendal, E.; Karahan, T. Applicability of Chlorophyll Meter Readings as Yield Predictor in Durum Wheat. Journal of Plant Nutrition 2010, 34, 151-164, doi:10.1080/01904167.2011.533319.

27. Lichtenthaler, H.K.; Babani, F. Detection of Photosynthetic Activity and Water Stress by Imaging the Red Chlorophyll Fluorescence. Plant Physiology and Biochemistry 2000, 38, 889-895, doi:10.1016/S0981-9428(00)01199-2.

28. Humphry, J.B.; Daniel, T.C.; Edwards, D.R.; Sharpley, A.N. A Portable Rainfall Simulator for Plot-Scale Runoff Studies. Applied Engineering in Agriculture 2002, 18, 6.

29. Lawrimore, J.H.; Menne, M.J.; Gleason, B.E.; Williams, C.N.; Wuertz, D.B.; Vose, R.S.; Rennie, J. An Overview of the Global Historical Climatology Network Monthly Mean Temperature Data Set, Version 3. Journal of Geophysical Atmospheres: Atmospheres 2011, 116.

30. Tasnim, R.; Zhang, Y.J. Are Wild Blueberries a Crop with Low Photosynthetic Capacity? Chamber-Size Effects in Measuring Photosynthesis. Agronomy 2021, 11, doi:https://doi.org/10.3390/agronomy11081572.

31. Hou, W.; Shen, J.; Xu, W.; Khan, M.R.; Wang, Y.; Zhou, X.; Gao, Q.; Murtaza, B.; Zhang, Z. Recommended Nitrogen Rates and the Verification of Effects Based on Leaf SPAD Readings of Rice. PeerJ 2021, 9, e12107, doi:10.7717/peerj.12107.

32. Hirte, J.; Leifeld, J.; Abiven, S.; Oberholzer, H.-R.; Hammelehle, A.; Mayer, J. Overestimation of Crop Root Biomass in Field Experiments Due to Extraneous Organic Matter. Frontiers in Plant Science 2017, 8, 284, doi:10.3389/fpls.2017.00284.

33. USDA-NRCS Above-Ground Biomass (Plant) Determinations; United States Department of Agriculture Natural Resources Conservation Service, National Soil Survey Center: Lincoln, NE, n.d.; pp. 1-2;.

34. McCullagh, P.; Nelder, J.A. Generalized Linear Models; 2nd ed.; Chapman and Hall/CRC: Boca Raton, FL, 1989;

35. Venables, W.N.; Ripley, B.D.; Venables, W.N. Modern Applied Statistics with S; Statistics and computing; 4th ed.; Springer: New York, 2002; ISBN 978-0-387-95457-8.

36. Mekis, E.; Hogg, W.D. Rehabilitation and Analysis of Canadian Daily Precipitation Time Series. Atmosphere-Ocean 1999, 37, 53-85, doi:10.1080/07055900.1999.9649621.

37. Ng, V.K.Y.; Cribbie, R.A. Using the Gamma Generalized Linear Model for Modeling Continuous, Skewed and Heteroscedastic Outcomes in Psychology. Curr Psychol 2017, 36, 225-235, doi:10.1007/s12144-015-9404-0.

38. R Core Team R: A Language and Environment for Statistical Computing; R Foundation for Statistical Computing: Vienna, Austria, 2021;

39. Wickham, H. GGplot2: Elegant Graphics for Data Analysis; Springer-Verlag: New York, 2016;

40. Tjosvold, S.A. Soil Mixes Part 3: How Much Air and Water?; University of California, Agriculture and Natural Resources: California, 2019;

41. Hess, L.J.T.; Hinckley, E.-L.S.; Robertson, G.P.; Matson, P.A. Rainfall Intensification Increases Nitrate Leaching from Tilled but Not No-till Cropping Systems in the U.S. Midwest. Agriculture, Ecosystems \& Environment 2020, 290, 106747, doi:10.1016/j.agee.2019.106747.

42. Fierer, N.; Schimel, J.P. Effects of Drying-Rewetting Frequency on Soil Carbon and Nitrogen Transformations. Soil Biology and Biochemistry 2002, 34, 777-787, doi:10.1016/S0038-0717(02)00007-X.

43. Yahdjian, L.; Sala, O.E. Size of Precipitation Pulses Controls Nitrogen Transformation and Losses in an Arid Patagonian Ecosystem. Ecosystems 2010, 13, 575-585, doi:10.1007/s10021-010-9341-6.

44. Hess, L.J.T.; Hinckley, E.-L.S.; Robertson, G.P.; Hamilton, S.K.; Matson, P.A. Rainfall Intensification Enhances Deep Percolation and Soil Water Content in Tilled and No-Till Cropping Systems of the US Midwest. Vadose Zone Journal 2018, 17, 180128, doi:10.2136/vzj2018.07.0128.

45. Van Metre, P.C.; Frey, J.W.; Musgrove, M.; Nakagaki, N.; Qi, S.; Mahler, B.J.; Wieczorek, M.E.; Button, D.T. High Nitrate Concentrations in Some Midwest United States Streams in 2013 after the 2012 Drought. Journal of Environmental Quality 2016, 45, 1696-1704, doi:10.2134/jeq2015.12.0591.

46. Sosnowski, M.R.; Ayres, M.R.; Scott, E.S. The Influence of Water Deficit Stress on the Grapevine Trunk Disease Pathogens Eutypa Lata and Diplodia Seriata. Plant Disease 2021, 105, 2217-2221, doi:10.1094/PDIS-07-20-1538-RE.

47. Rossi, F.G.; Asalf, B.; Grieu, C.; Onofre, R.B.; Peres, N.A.; Gadoury, D.M.; Stensvand, A. Effect of Water Stress on Reproduction and Colonization of Podosphaera Aphanis of Strawberry. Plant Disease 2020, 104, 2973-2978, doi:10.1094/PDIS-10-19-2172-RE.

48. Razavi, F.; Pollet, B.; Steppe, K.; van Labeke, M.C. Chlorophyll Fluorescence as a Tool for Evaluation of Drought Stress in Strawberry. Photosynthetica 2008, 46, 631-633, doi:10.1007/s11099-008-0108-7. 
49. Flexas, J.; Escalona, J.M.; Medrano, H. Water Stress Induces Different Levels of Photosynthesis and Electron Transport Rate Regulation in Grapevines. Plant, Cell \& Environment 1999, 22, 39-48, doi:10.1046/j.1365-3040.1999.00371.x.

50. Flexas, J.; Bota, J.; Escalona, J.M.; Sampol, B.; Medrano, H. Effects of Drought on Photosynthesis in Grapevines under Field Conditions: An Evaluation of Stomatal and Mesophyll Limitations. Functional Plant Biol. 2002, 29, 461-471, doi:10.1071/pp01119.

51. Ghaderi, N.; Siosemardeh, A. Response to Drought Stress of Two Strawberry Cultivars (Cv. Kurdistan and Selva). Hortic. Environ. Biotechnol. 2011, 52, 6-12, doi:10.1007/s13580-011-0019-6.

52. Mann, C.E.T. Studies in the Root and Shoot Growth of the Strawberry. V. The Origin, Development, and Function of the Roots of the Cultivated Strawberry (Fragaria Virginiana X Chiloensis). Annals of Botany 1930, 44, 55-86.

53. Brouder, S.M.; Volenec, J.J. Impact of Climate Change on Crop Nutrient and Water Use Efficiencies. Physiologia Plantarum 2008, 133, 705-724, doi:10.1111/j.1399-3054.2008.01136.x.

54. Martínez-Ferri, E.; Soria, C.; Ariza, M.T.; Medina, J.J.; Miranda, L.; Domíguez, P.; Muriel, J.L. Water Relations, Growth and Physiological Response of Seven Strawberry Cultivars (Fragaria×ananassa Duch.) to Different Water Availability. Agricultural Water Management 2016, 164, 73-82, doi:10.1016/j.agwat.2015.08.014.

55. Savé, R.; Peñuelas, J.; Marfà, O.; Serrano, L. Changes in Leaf Osmotic and Elastic Properties and Canopy Structure of Strawberries under Mild Water Stress. HortScience 1993, 28, 925-927, doi:10.21273/HORTSCI.28.9.925.

56. Tasnim, R.; Drummond, F.; Zhang, Y.J. Climate Change Patterns of Wild Blueberry Fields in Downeast, Maine over the Past 40 Years. Water 2021, 13, 594, doi:10.3390/w13050594. 